\title{
Nitrogen-Doped Carbon-Coating Disproportionated SiO Materials as Long Cycling Stable Anode for Lithium Ion Batteries
}

\author{
Ben Huang ${ }^{1}$, Binbin Chu ${ }^{1}$, Tao Huang ${ }^{2, *}$ and Aishui $\mathrm{Yu}^{1, * \mathbb{D}}$ \\ 1 Collaborative Innovation Center of Chemistry for Energy Materials, Shanghai Key Laboratory of Molecular \\ Catalysis and Innovative Materials, Department of Chemistry, Institute of New Energy, Fudan University, \\ Shanghai 200438, China; bhuang18@fudan.edu.cn (B.H.); 18110220027@fudan.edu.cn (B.C.) \\ 2 Laboratory of Advanced Materials, Fudan University, Shanghai 200438, China \\ * Correspondence: huangt@fudan.edu.cn (T.H.); asyu@fudan.edu.cn (A.Y.)
}

Citation: Huang, B.; Chu, B.; Huang, T.; Yu, A. Nitrogen-Doped CarbonCoating Disproportionated SiO Materials as Long Cycling Stable Anode for Lithium Ion Batteries. Molecules 2021, 26, 1536. https:// doi.org/10.3390/molecules26061536

Academic Editors: Raul-Augustin Mitran and Mihaela Ramona Buga

Received: 6 February 2021

Accepted: 9 March 2021

Published: 11 March 2021

Publisher's Note: MDPI stays neutral with regard to jurisdictional claims in published maps and institutional affiliations.

Copyright: (c) 2021 by the authors. Licensee MDPI, Basel, Switzerland. This article is an open access article distributed under the terms and conditions of the Creative Commons Attribution (CC BY) license (https:// creativecommons.org/licenses/by/ $4.0 /)$.

\begin{abstract}
Silicon monoxide $(\mathrm{SiO})$ is a kind of promising anode material for lithium-ion batteries because of its smaller volume change during the charge and discharge process than pure silicon and its higher theoretical capacity than commercialized graphite. However, its fast-fading capacity still restricts the development of practical application of $\mathrm{SiO}$. A simple and cheap strategy to dope nitrogen and coat carbon on the surface of disproportionated $\mathrm{SiO}$ is proposed to improve the cycling stability significantly even at a high specific current. The capacity retention is nearly $85 \%$ after 250 cycles and more than $69 \%$ after 500 cycles at a specific current of $1000 \mathrm{~mA} \mathrm{~g}^{-1}$. Even at a specific current of $2000 \mathrm{~mA} \mathrm{~g}^{-1}$, its cycling performance behaves similarly to that of $1000 \mathrm{~mA} \mathrm{~g}^{-1}$. Nitrogen doping in materials could improve the conductivity of materials because pyridinic nitrogen and pyrrolic nitrogen could improve the electron conductivity and provide defects to contribute to the diffusion of lithium ions. The use of pitch and melamine, which are easily available industrial raw materials, makes it possible to contribute to the practical application.
\end{abstract}

Keywords: lithium ion batteries; anode; silicon; carbon coating; nitrogen-doped; high energy density

\section{Introduction}

Nowadays, lithium ion batteries (LIBs) have conquered the portable electronics and new-energy vehicles markets of because of their advantages in energy density, lifespan and positive relationship to the environment. LIBs have become known as one of the most attractive energy storage devices, providing significant contributions in modern society. Meanwhile, the fast development of new energy vehicles and portable electronics has also stimulated the development and investigation of LIBs with higher energy and power density. In 2019, three scientists won the Nobel Prize in Chemistry for their excellent contributions to the development of LIBs [1]. A growing number of studies have been investigated for LIBs with higher energy density and higher cycling stability [2,3].

The energy density of LIBs mainly depends on their cathode and anode materials. For cathode materials, many kinds of materials, such as $\mathrm{LiCoO}_{2}, \mathrm{LiNi}_{\mathrm{x}} \mathrm{Co}_{\mathrm{y}} \mathrm{Al}_{1-\mathrm{x}-\mathrm{y}} \mathrm{O}_{2}$, $\mathrm{LiNi}_{\mathrm{x}} \mathrm{Mn}_{\mathrm{y}} \mathrm{Co}_{1-\mathrm{x}-\mathrm{y}} \mathrm{O}_{2}$, etc., were investigated and modified to improve their capacity, cycling performance, rate performance and other capabilities [4-6], while their actual specific capacity is close to their theoretical capacity, which means that it is difficult to improve their capacity significantly. For anode, carbon-based materials were widely used in commercialized batteries because they perform well in cycling and rate performance. However, to improve the energy density further, new materials must be investigated because the theoretical specific capacity of carbon $\left(372 \mathrm{~mA} \mathrm{~h} \mathrm{~g}^{-1}, \mathrm{LiC}_{6}\right)$ is relatively low [7]. Silicon ( $\mathrm{Si}$ )-based materials were found to display the highest theoretical specific capacity $\left(4200 \mathrm{~mA} \mathrm{~h} \mathrm{~g}{ }^{-1}\right.$ for $\mathrm{Li}_{22} \mathrm{Si}_{5}$ at $400{ }^{\circ} \mathrm{C}$, generally is $3579 \mathrm{~mA} \mathrm{~h} \mathrm{~g}{ }^{-1}$ for $\mathrm{Li}_{15} \mathrm{Si}_{4}$ at room temperature) among all anode materials for LIBs [8-15]. However, pure silicon undergoes drastic volume changes during the charging and discharging process, leading 
to an unstable Si structure and solid electrolyte interphase (SEI) layer, causing a poor cycling lifespan $[11,16,17]$. Silicon monoxide $(\mathrm{SiO})$ delivers a lower volume change than pure silicon. It is also abundant, cheap and could be produced easily, which means that $\mathrm{SiO}$ is a possible anode material that can replace pure $\mathrm{Si}$ for next generation lithium ion batteries [18]. However, $\mathrm{SiO}$ also suffers from several serious problems such as low intrinsic electrical conductivity, non-negligible volume change and low initial Coulombic efficiency (ICE) [18]. For ICE, some methods of pre-lithiation on anode materials or electrodes have been reported. Our group has also reported a kind of pre-lithiation method using stabilized lithium metal powder (SLMP) to improve ICE easily [19]. However, it could not improve the cycling performance. $\mathrm{SiO}$ material must be modified before it could be used as anode material for lithium ion batteries in practical application.

For bare $\mathrm{SiO}$, many strategies, such as downsizing, constructing porous structures, nano-compositing were used to solve the problem of drastic volume change [20-25]. Sohn et al. employed high-energy mechanical milling (HEMM) process to combine disproportionated $\mathrm{SiO}(\mathrm{d}-\mathrm{SiO})$ based anode combined with nanosized $\mathrm{Si}$. This kind of material delivered a high reversible specific capacity of about $1000 \mathrm{~mA} \mathrm{~h} \mathrm{~g}^{-1}$ with good capacity retention [22]. $\mathrm{NaOH}$ solution was used to etch $\mathrm{SiO}_{2}$ matrix in d-SiO to produce porous $\mathrm{SiO}_{\mathrm{x}}$ without carbon coating, which demonstrated a high specific capacity of around $1240 \mathrm{~mA} \mathrm{~h} \mathrm{~g}^{-1}$ even after 100 cycles [20]. These strategies make bare $\mathrm{SiO}$ materials behave a relatively stable cycling performance with a high specific capacity. However, most obtained specific capacities were based on a low current density. For $\mathrm{SiO} / \mathrm{C}$ composite, it is easy to deliver a better cycling performance because of the excellent electrochemical performance of $\mathrm{C}$. A kind of $\mathrm{SiO} / \mathrm{C}$ composite prepared by Ohzuku's group manifested a discharge capacity of $700 \mathrm{~mA} \mathrm{~h} \mathrm{~g}^{-1}$ after 100 cycles [26]. Oh et al. also reported a micrometer-sized d-SiO/C composite with good electrochemical performance $[27,28]$. Though the compositing with $\mathrm{C}$ is a good way to improve cycling stability, the prepared active materials perform poor rate capability. To tackle this issue, $\mathrm{N}$ element was used to dope in the coating layer. Tu et al. proposed a kind of anode material with core-shell structure of porous silicon and $\mathrm{N}$-doped C layer (p-Si/NC) [29]. There were three kinds of $\mathrm{N}$ atoms in the coating layer, leading to produce active sites in $C$ layers which could contribute the lithium ions diffusion. This kind of electrode delivered a capacity of $750 \mathrm{~mA} \mathrm{~h} \mathrm{~g}^{-1}$ after 200 cycles under $200 \mathrm{~mA} \mathrm{~g}^{-1}$ with a capacity retention of $73 \%$. It also performs well in rate performance. Choi et al. fabricated $\mathrm{N}$-doped carbon coated $\mathrm{SiO}(\mathrm{SiO} / \mathrm{NC})$ using $\mathrm{N}$-containing ionic liquid, delivering enhanced capacity and rate capability [30]. However, this strategy is not suitable in industry because of the high cost of ionic liquid. Cheap raw materials need to be searched and investigated to make $\mathrm{N}$-doped $\mathrm{C}$-coating $\mathrm{SiO}$ based materials available to the production of industry.

In this work, cheap and available pitch and melamine were used as $\mathrm{C}$ source and $\mathrm{N}$ source to coat disproportionated $\mathrm{SiO}(\mathrm{d}-\mathrm{SiO})$. The prepared active material (d-SiO-NC) delivered relative stable cycling stability especially at a high current density. This strategy is easy to be operated in industrial production because of the convenience of the process and the low price and availability of raw materials. The capacity retention of this material arrived $85 \%$ after 250 cycles and $69 \%$ after 500 cycles at a specific current of $1000 \mathrm{~mA} \mathrm{~g}^{-1}$. Besides, there is no obvious change in reversible specific capacity between the specific current of 1000 and $2000 \mathrm{~mA} \mathrm{~g}^{-1}$. Good cycling capability and rate performance make it become a promising anode material in next generation lithium ion batteries.

\section{Results and Discussion}

\subsection{Materials Preparation}

Figure 1 shows the schematic illustration of preparing $\mathrm{N}$-doped $\mathrm{C}$-coating disproportionated $\mathrm{SiO}$ (d-SiO-NC). When pristine $\mathrm{SiO}$ was heated to $900{ }^{\circ} \mathrm{C}$ under an argon atmosphere, $\mathrm{SiO}$ was partly disproportionated. [31] According to the literature report, there would be three different kinds of $\mathrm{N}$ in the coating layer after coating process [29], which would produce some defects in the $\mathrm{C}$ layer and further contribute to the lithium 
ions transport. To sum up, the disproportion of $\mathrm{SiO}, \mathrm{N}$-doped and C-coating improve the electrochemical performance jointly.

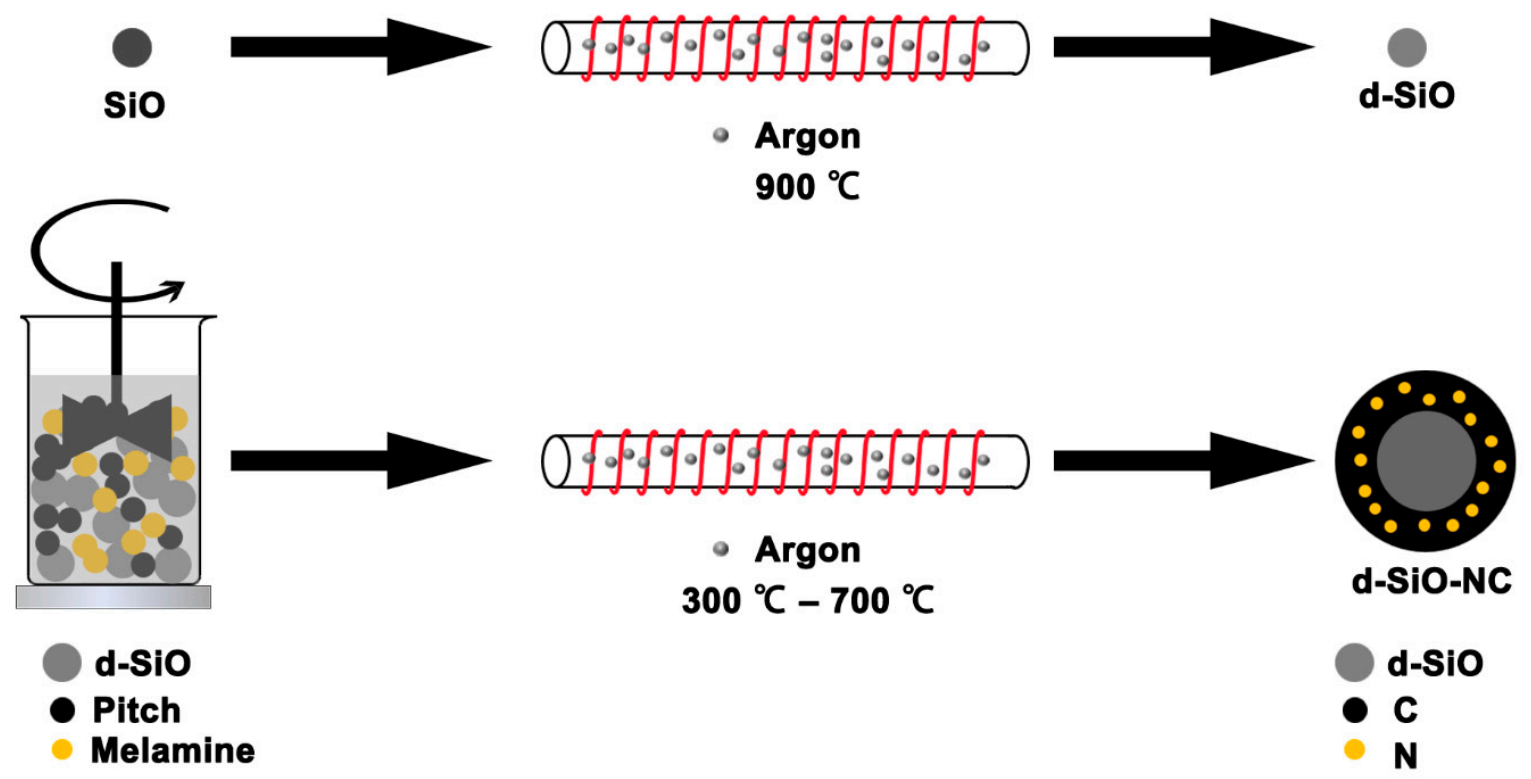

Figure 1. Schematic illustration of preparing nitrogen-doped carbon-coating disproportionated silicon monoxide (d-SiO-NC).

\subsection{Materials Morphology}

XRD patterns were used to characterize pristine $\mathrm{SiO}, \mathrm{d}-\mathrm{SiO}$, and d-SiO-NC (2:1.5:3) materials (Figure 2). Compared with pattern of pristine $\mathrm{SiO}$ and $\mathrm{d}-\mathrm{SiO}$, the diffraction peak at about $28.4^{\circ}, 47.4^{\circ}$ and $56.2^{\circ}$ corresponding to the typical plane of $\mathrm{Si}(111), \mathrm{Si}(220)$ and $\mathrm{Si}$ (311) [32] are stronger in pattern of $\mathrm{d}-\mathrm{SiO}$ than those of $\mathrm{SiO}$, indicating that after heated at $900{ }^{\circ} \mathrm{C}$, crystal $\mathrm{Si}$ was produced successfully after disproportion of SiO. Besides, a broad peak at about $23.4^{\circ}$ appeared in the pattern of d-SiO-NC, which suggests that carbon was obtained during the carbonization process.



Figure 2. XRD patterns of pristine $\mathrm{SiO}, \mathrm{d}-\mathrm{SiO}$, and d-SiO-NC (2:1.5:3). 
The morphology of materials was characterized and investigated by SEM and TEM (Figure 3a-e). Pristine $\mathrm{SiO}$ is combined with a large amount of small and uniform particles with an average diameter of 3-6 $\mu \mathrm{m}$ (Figure 3a). After heated, there is no obvious change in the particles' shape and size (Figure 3b). Different sizes of particles could be found in the SEM pattern of $\mathrm{d}-\mathrm{SiO}-\mathrm{NC}$ (Figure 3c), suggesting that $\mathrm{N}$ and $\mathrm{C}$ may coat on the surface of $\mathrm{d}-\mathrm{SiO}$ successfully. In the TEM pattern of d-SiO-NC (Figure 3d), a layer with about $20 \mathrm{~nm}$ thick could be found on the surface of particles, further proving that d-SiO was coated successfully. Some lattice fringe of Si could be found in the HRTEM pattern and selected-area diffraction (SAD) of d-SiO-NC (Figure 3e), indicating that some crystal Si was produced during the disproportion process. The formation of crystal Si would contribute to improving specific capacity, while partially developed several-nanometers Si performs a poor volume change. According to the TEM element mapping image (Figure 3g-1), N was uniformly doped in the active materials, while $C$ was also distributed in the particles.

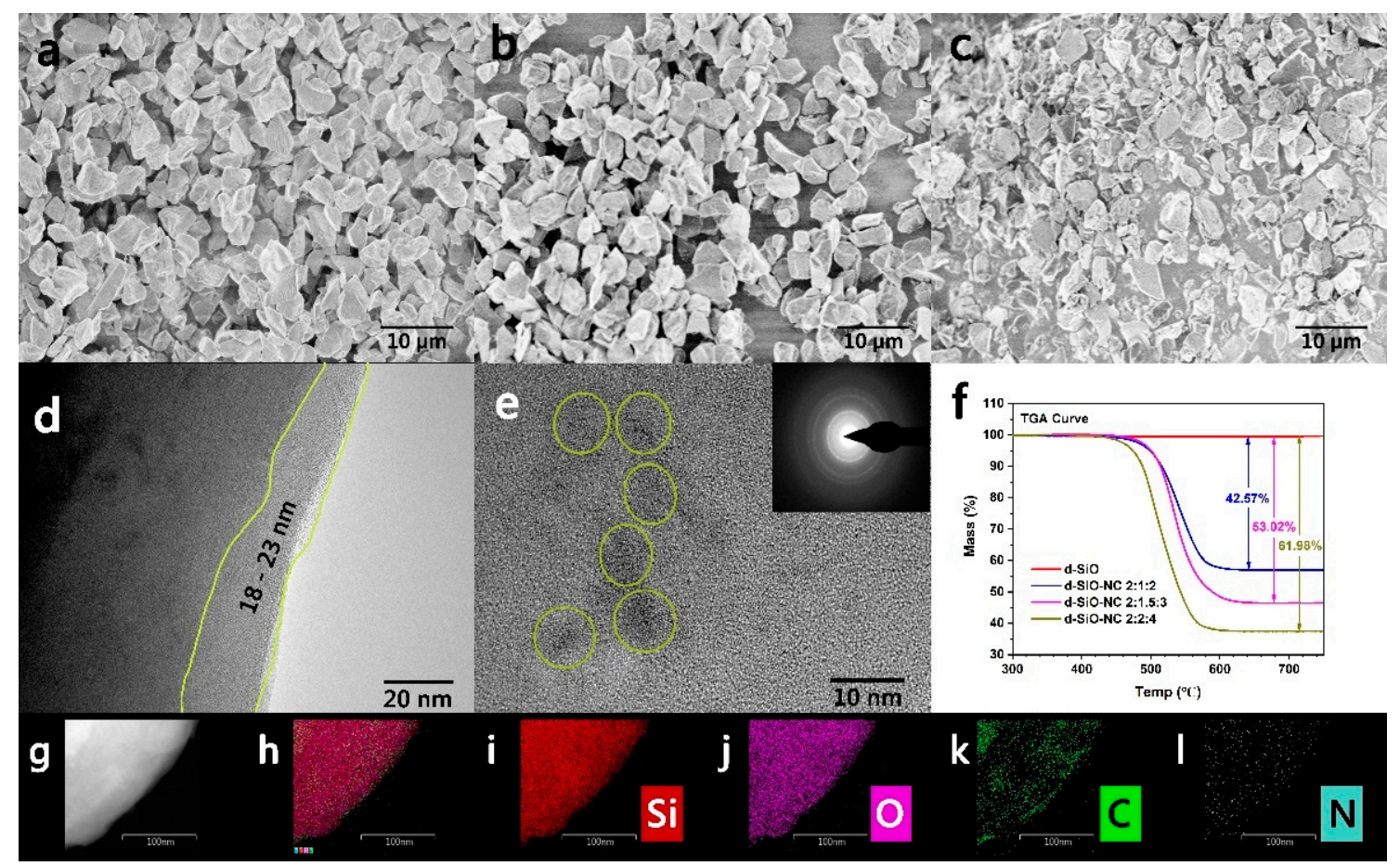

Figure 3. SEM patterns of pure $\mathrm{SiO}(\mathbf{a}), \mathrm{d}-\mathrm{SiO}(\mathbf{b})$ and d-SiO-NC (2:1.5:3) (c). (d) TEM images of the coating layer of d-SiO-NC (2:1.5:3). (e) TEM images of the inner part of d-SiO-NC (2:1.5:3) with the corresponding lattice spacing. (f) TG curve of d-SiO-NC (2:1.5:3) with different ratio of raw materials. (g-1) Element mapping images of d-SiO-NC (2:1.5:3) (Scale bar: $100 \mathrm{~nm})$.

Different mass ratios of $\mathrm{d}-\mathrm{SiO}$, melamine and pitch $(2: 2: 4,2: 1.5: 3$ and 2:1:2) were used to prepare d-SiO-NC materials. To confirm the element content, thermogravimetric analysis (TGA) was operated on three different kinds of synthesized materials. TGA curve was shown in Figure 3f. The content of d-SiO could be calculated according to the curve. After calculation, the mass ratio of $\mathrm{d}-\mathrm{SiO}$ in three different kinds of materials are $57.43 \%, 46.88 \%$ and $38.02 \%$. After further calculation, the contents of $\mathrm{N}$ and $\mathrm{C}$ in three materials could be calculated and shown in Table 1.

Table 1. The content of $\mathrm{d}-\mathrm{SiO}, \mathrm{N}$ and $\mathrm{C}$ in three kinds of prepared d-SiO-NC materials.

\begin{tabular}{cccc}
\hline d-SiO:Melamine:Pitch & d-SiO Content & N Content & C Content \\
\hline $2: 1: 2$ & $57.43 \%$ & $4.73 \%$ & $37.84 \%$ \\
$2: 1.5: 3$ & $46.88 \%$ & $5.89 \%$ & $47.13 \%$ \\
$2: 2: 4$ & $38.02 \%$ & $6.89 \%$ & $55.09 \%$ \\
\hline
\end{tabular}


To further confirm the chemical state on the particle surface of the composites, XPS experiments were performed. The binding energies were calibrated with respect to the $\mathrm{C}$ 1s peak at $284.6 \mathrm{eV}$. Figure 4 a shows the high-resolution spectrum of $\mathrm{Si} 2 \mathrm{p}$. The peaks at $104 \mathrm{eV}, 102.9 \mathrm{eV}$ and $102 \mathrm{eV}$ represent $\mathrm{Si}^{4+}, \mathrm{Si}^{3+}$ and $\mathrm{Si}^{2+}$, respectively, indicating that there is a large amount of $\mathrm{SiO}_{2}$ on the surface of particles, while the peak at $99.9 \mathrm{eV}$, which represents $\mathrm{Si}^{0}$, is barely visible. The disproportion reaction might lead to produce more crystal $\mathrm{Si}$ in the particle while more $\mathrm{SiO}_{2}$ on the surface of the particle [33,34]. Figure $4 \mathrm{~b}$ displays the spectrum of $\mathrm{O} 1 \mathrm{~s}$. There is one main peak $(533.1 \mathrm{eV})$ corresponding to the $\mathrm{Si}-\mathrm{O}$ bond that could be found. Figure $4 \mathrm{c}$ shows the spectrum of $\mathrm{C} 1 \mathrm{~s}$. The peak can be divided into three peaks at $284.6 \mathrm{eV}, 285.8 \mathrm{eV}$ and $288.1 \mathrm{eV}$, which represent $\mathrm{C}-\mathrm{C}, \mathrm{C}=\mathrm{N}$ and $\mathrm{C}-\mathrm{N}$ bonds, respectively $[29,35]$. The appearance of peaks corresponding to the $\mathrm{C}=\mathrm{N}$ and $\mathrm{C}-\mathrm{N}$ bond suggests that $\mathrm{N}$ has been successfully doped into the layer of carbon. It could be also indicated that double bonds exist more between $C$ and N. Figure $4 \mathrm{~d}$ shows the spectrum of $\mathrm{N} 1 \mathrm{~s}$. Three peaks referring to pyridinic $\mathrm{N}(398.2 \mathrm{eV})$, pyrrolic $\mathrm{N}(399.5 \mathrm{eV})$ and quaternary $\mathrm{N}(400.8 \mathrm{eV})$ could be divided after split process [29]. Among all three kinds of $\mathrm{N}$, pyridinic $\mathrm{N}$ and pyrrolic $\mathrm{N}$ could improve the electron conductivity and provide defects to contribute to the diffusion of lithium ions.

a

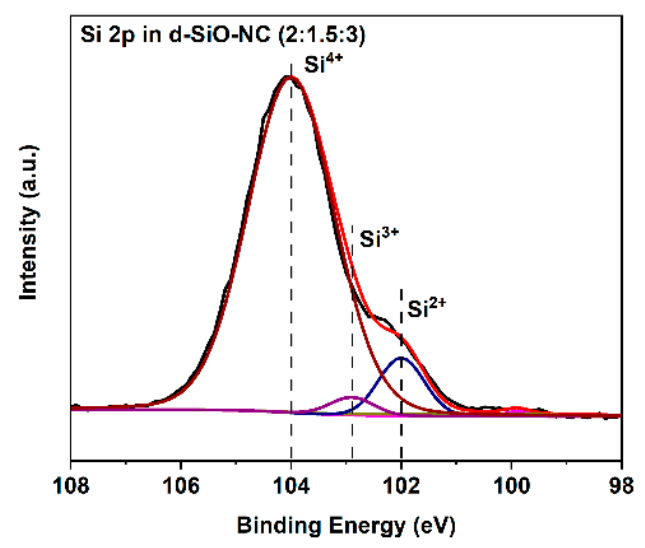

C



b

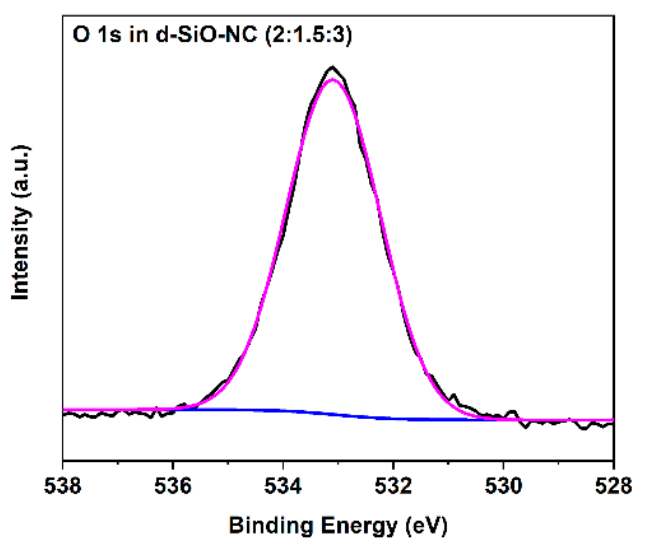

d

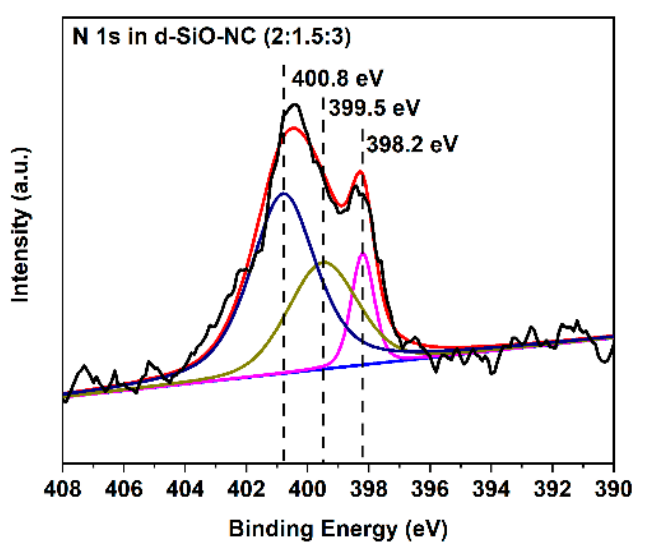

Figure 4. XPS spectra of d-SiO-NC (2:1.5:3). (a) Si 2p, (b) C 1s, (c) O 1s, (d) N 1s.

\subsection{Electrochemical Performance in Half Cells}

The cycling performances at a specific current of $1000 \mathrm{~mA} \mathrm{~g}^{-1}$ of pristine $\mathrm{SiO}, \mathrm{d}-\mathrm{SiO}$, d-SiO-C (2:4.5) and d-SiO-NC (2:1.5:3) are shown and compared in Figure 5a. The specific capacity of $\mathrm{SiO}$ and d-SiO show an obvious decrease as the cycling process, while after coating, the capacity retention improved a lot. Compared to pure C-coating (blue squares) with $\mathrm{N}$-doped $\mathrm{C}$-coating (pink squares), $\mathrm{N}$-doped $\mathrm{C}$-coating $\mathrm{d}$-SiO performs a more stable 
cycling performance. After 250 cycles at a specific current of $1000 \mathrm{~mA} \mathrm{~g}^{-1}$, its specific capacity was still more than $400 \mathrm{~mA} \mathrm{~h} \mathrm{~g}^{-1}$ with a capacity retention of more than $85 \%$, showing a more stable cycling performance than that of only C-coating. Figure $5 \mathrm{~b}$ shows the detailed Coulombic efficiency of pristine $\mathrm{SiO}, \mathrm{d}-\mathrm{SiO}, \mathrm{d}-\mathrm{SiO}-\mathrm{C}(2: 4.5)$ and d-SiO-NC (2:1.5:3). It could be indicated that the Coulombic efficiency improves quickly to nearly 99.8\% and keeps stable after coating. d-SiO-NC (2:1.5:3) performs best among all four kinds of materials considering Figure $5 \mathrm{a}, \mathrm{b}$. On the other hand, considering the effect of different ratios of raw materials, active materials composed with different ratios of $\mathrm{d}-\mathrm{SiO}$, melamine and pitch (2:2:4, 2:1.5:3 and 2:1:2) were prepared to investigate their cycling performance. Figure $5 \mathrm{c}$ shows the comparison of cycling performance among them. When the mass ratio of $\mathrm{d}-\mathrm{SiO}$, melamine and pitch is $2: 2: 4, \mathrm{~d}-\mathrm{SiO}-\mathrm{NC}$ shows a relatively stable cycling performance; however, its reversible specific capacity is really low. d-SiO-NC (2:1.5:3) and d-SiO-NC (2:1:2) both perform good cycling stability and high specific capacity, in which d-SiO-NC (2:1.5:3) shows higher capacity retention (85\%) than d-SiO-NC (2:1:2) (73\%) after 250 cycles at a specific current of $1000 \mathrm{~mA} \mathrm{~g}^{-1}$. Figure $5 \mathrm{~d}$ shows the charge/discharge voltage profiles of $\mathrm{d}-\mathrm{SiO}-\mathrm{NC}(2: 1.5: 3)$ at different cycles. Its first discharge voltage profile shows a distinct plateau at $1.1 \mathrm{~V}$, which represents the formation of the SEI layer. There were no obvious changes among the charge/discharge voltage profile at 10,50 and 100 cycles, indicating the relative stability of this kind of material. To verify its cycling stability further, d-SiO-NC-based half cells were cycled for 500 cycles at two different specific currents of 1000 and $2000 \mathrm{~mA} \mathrm{~g}^{-1}$. The obvious change of specific capacity between two currents could be only found before the 50th cycle, while the specific capacity increased obviously at $2000 \mathrm{~mA} \mathrm{~g}^{-1}$ because enough time and cycles are necessary for materials activation and sufficient infiltration of electrolyte. After 50 cycles, the half cells both show a stable performance and high capacity retention $\left(69 \%\right.$ and $66 \%$ at 1000 and $2000 \mathrm{~mA} \mathrm{~g}^{-1}$, respectively). Besides, the difference of specific capacities at two different currents is also relatively small, indicating that this kind of anode material could also be applied in some situations under a high current density.

In Figure $5 \mathrm{a}, \mathrm{c}$, it could be found that when $\mathrm{SiO}$ was heated to produce d-SiO, their cycling performance decreased significantly. It seems that a higher specific capacity can arrive if pristine $\mathrm{SiO}$ was coated with $\mathrm{C}$ directly. To verify this idea, $\mathrm{SiO}-\mathrm{NC}$ was prepared and used to fabricate half cells for the cycling performance test (Figure 6). However, SiO$\mathrm{NC}$ only shows a relatively low cycling capacity in all mass ratios of $\mathrm{SiO}$, melamine and pitch (blue, pink and dark yellow squares in Figure 6a). Meanwhile, SiO-NC also delivers a larger irreversible capacity during the first discharge process than d-SiO-NC (Figure 6b). In Figure 6c, it could be indicated that SiO-NC-based half cells would get a Coulombic efficiency of $99.8 \%$ after about 20 cycles, which is slower than d-SiO-NC-based half cells (about 10 cycles) (Figure 5b). All mentioned above demonstrated that d-SiO-NC performs well than SiO-NC as anode for lithium ion batteries. This may because that crystal Si produced after heated may help provide a higher capacity; however, the disadvantage of pure Si would perform significantly if there is not a coating layer. Compared with the results reported in other literatures [29,30,36,37], d-SiO-NC also performs a better capability. Though similar capacity and cycling performance could be obtained in some of them, the specific current was usually relatively low, or expensive raw materials and complicated method was used during their synthesis process. 
a

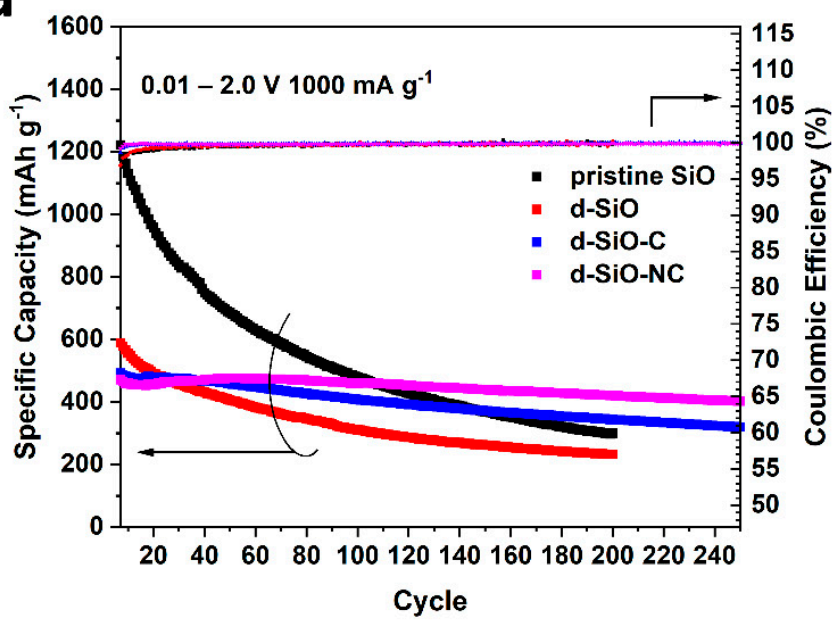

C



b

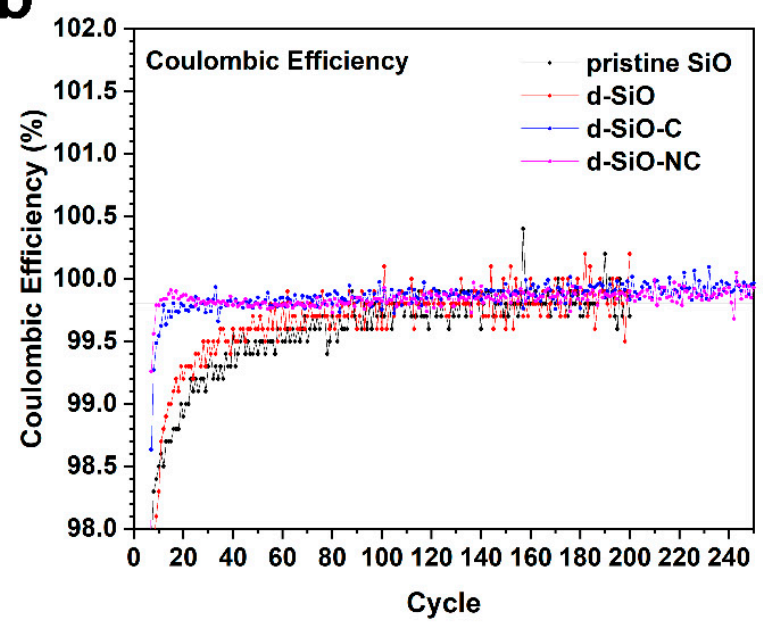

d

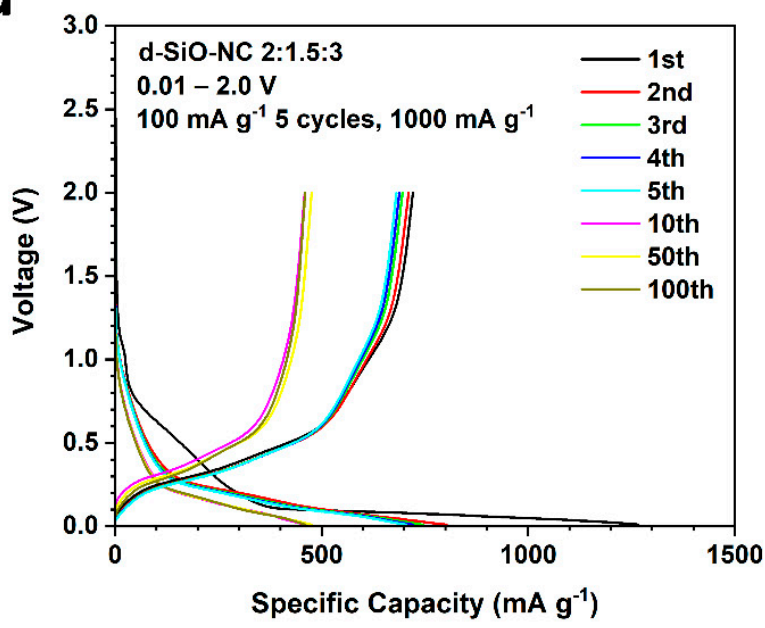

e

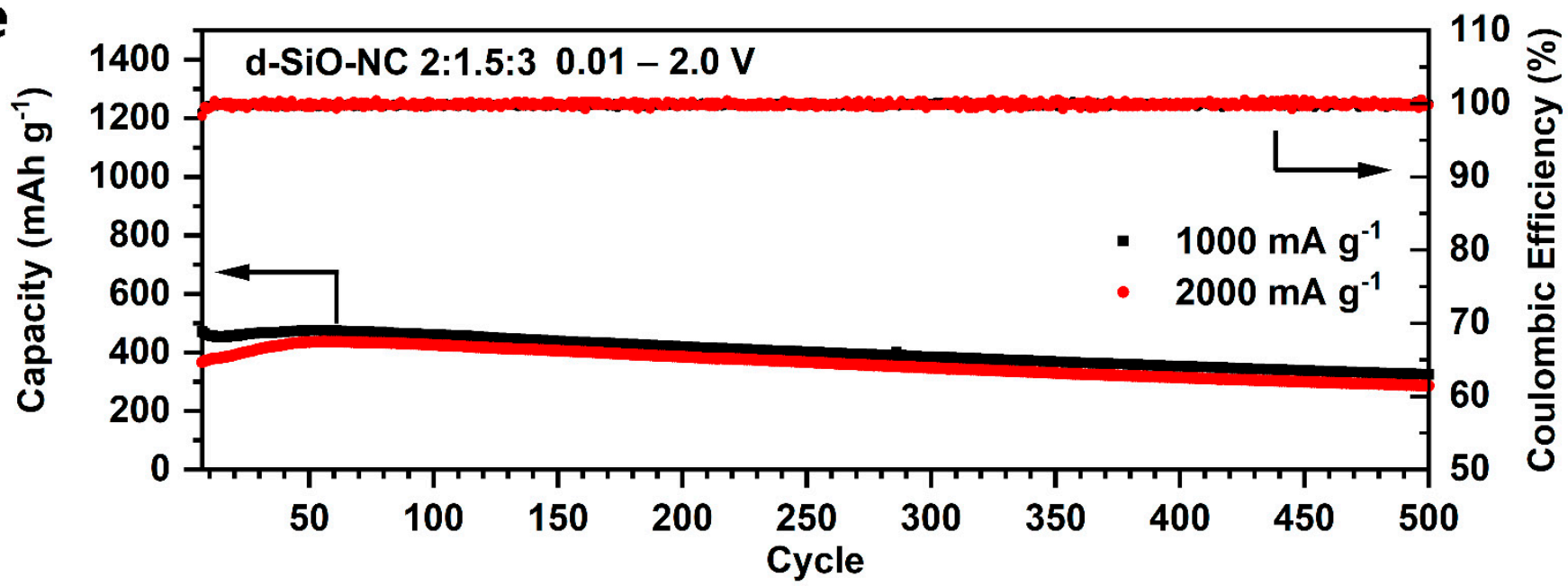

Figure 5. Cycling performance of half cells fabricated by pristine $\mathrm{SiO}, \mathrm{d}-\mathrm{SiO}, \mathrm{d}-\mathrm{SiO}-\mathrm{C}(2: 4.5)$ and d-SiO-NC (2:1.5:3) (a) and their Coulombic efficiency (b). (c) Cycling performance of half cells fabricated by pristine $\mathrm{SiO}, \mathrm{d}-\mathrm{SiO}$ and d-SiO-NC with different ratio of raw materials. (d) Charge/discharge voltage profiles of d-SiO-NC (2:1.5:3) in different cycles. (e) Long cycling performance at different current density of d-SiO-NC (2:1.5:3). 
a

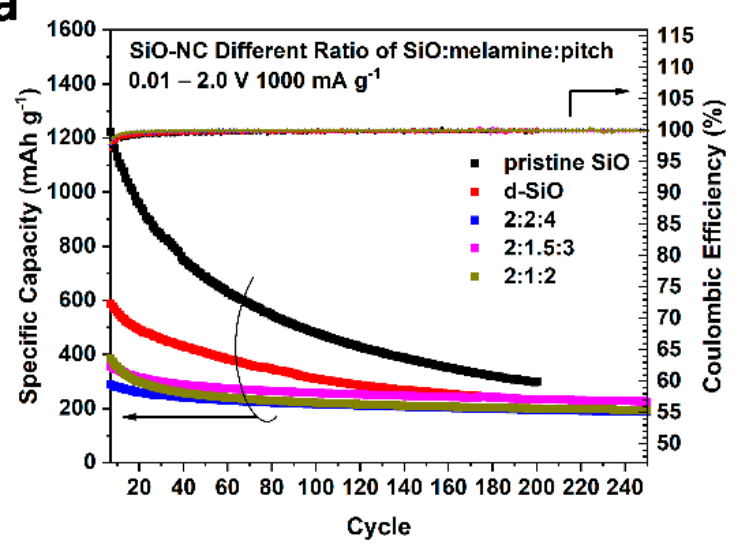

b



C

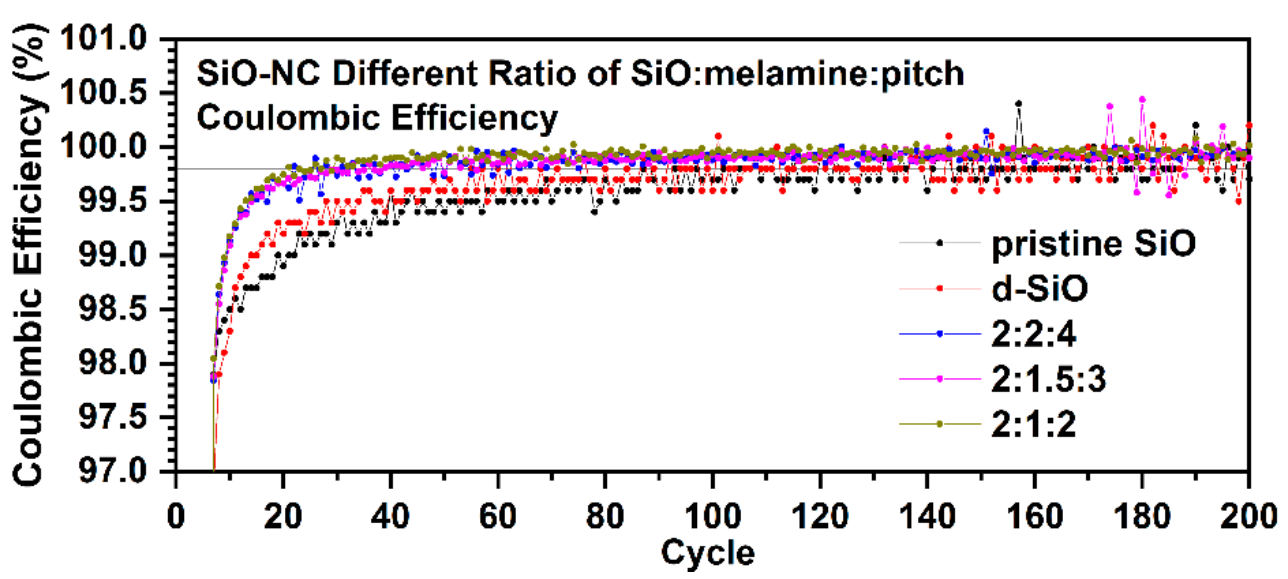

Figure 6. Cycling performance (a) and Coulombic efficiency (c) of pristine $\mathrm{SiO}, \mathrm{d}-\mathrm{SiO}, \mathrm{SiO}-\mathrm{NC}$ with different ratio of raw materials. (b) First charge/discharge voltage profile of $\mathrm{SiO}$, d-SiO, d-SiO-NC (2:1.5:3) and SiO-NC (2:1.5:3).

\subsection{CV and EIS Test and the Calculation of Chemical Diffusion Coefficient}

To investigate the difference between $\mathrm{N}$-doped and non-N-doped, CV and EIS tests were operated on the lithium half cells based on d-SiO-NC (2:1.5:3) and d-SiO-C (2:4.5) materials. Figure 7a,b show the CV curve of the first five cycles of d-SiO-NC (2:1.5:3)-based half cells and d-SiO-C (2:4.5)-based half cells. It can be found that during the first anode scan, a small peak at around $1.1 \mathrm{~V}$ and a broad peak at around $0.4-0.5 \mathrm{~V}$ can be found in both two graphs, while during the second anode scan, these two peaks disappeared, indicating that these two peaks are related to the decomposition of FEC in electrolyte, the formation of SEI layer and other irreversible reaction during the first discharge process. The peak at $0.2-0.3 \mathrm{~V}$ during the anodic scan represents the lithiation of $\mathrm{C}$ and $\mathrm{d}-\mathrm{SiO}$ materials. The peaks at 0.4 and $0.6 \mathrm{~V}$ during the cathodic scan represent the de-lithiation of $\mathrm{d}-\mathrm{SiO}$. The peak shape during the first cycle is significantly different from that of the following cycles, suggesting that the formation of the SEI layer and other irreversible reactions might consume a large amount of active lithium, causing a low initial Coulombic efficiency (ICE). This could also be demonstrated in cycling performance, which shows a low ICE of $56 \%$. To improve the ICE, SLMP was used to pre-lithiate d-SiO-NC (2:1.5:3) electrode. More details about pre-lithiation are described in the next part. Compared with Figure 7a,b, the intensity of the peak of d-SiO-NC (2:1.5:3)-based half cells increases faster than that of SiO-NC (2:4.5)-based half cells, indicating that the doping of $\mathrm{N}$ could accelerate the activation of active materials. This property can be used to reduce the formation time of batteries. Compared with the first cycle CV curve of two kinds of materials (Figure 7e), the peak at around $1.1 \mathrm{~V}$ of d-SiO-NC delivered lower intensity than that of d-SiO-C, while at around $0.4-0.5 \mathrm{~V}$, the peak of $\mathrm{d}-\mathrm{SiO}-\mathrm{NC}$ is more obvious than that of $\mathrm{d}-\mathrm{SiO}-\mathrm{C}$, indicating 
that the mechanism of active lithium loss during the first discharge process of two kinds of materials is different. $\mathrm{N}$ may restrict the irreversible reaction at $1.1 \mathrm{~V}$, while it contributes it at $0.4-0.5 \mathrm{~V}$.

a

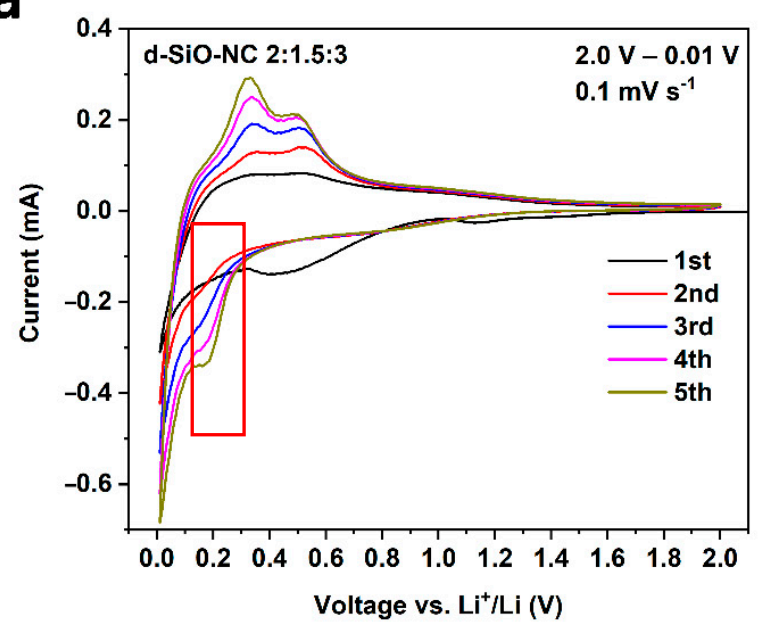

C

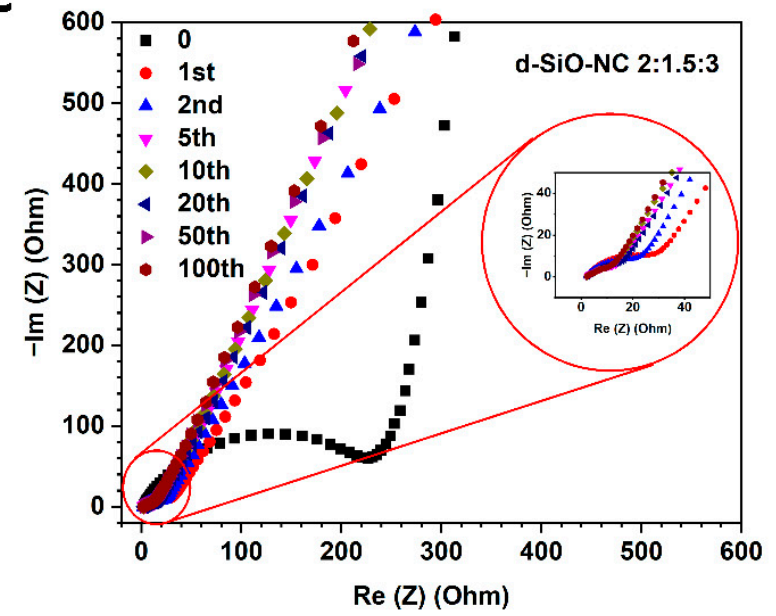

e

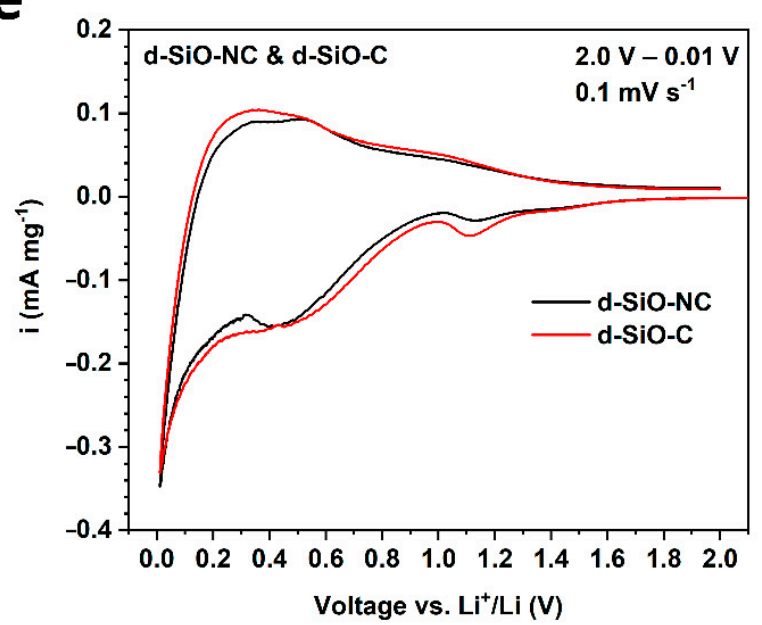

b

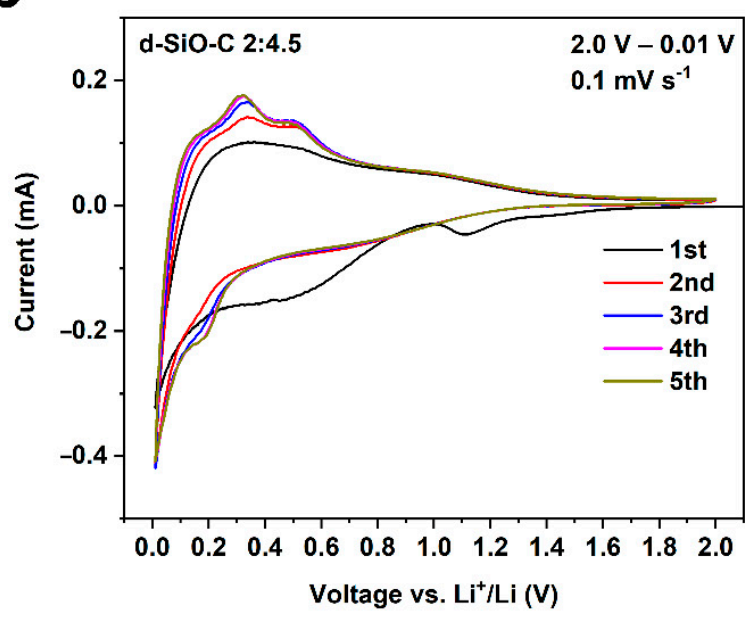

d

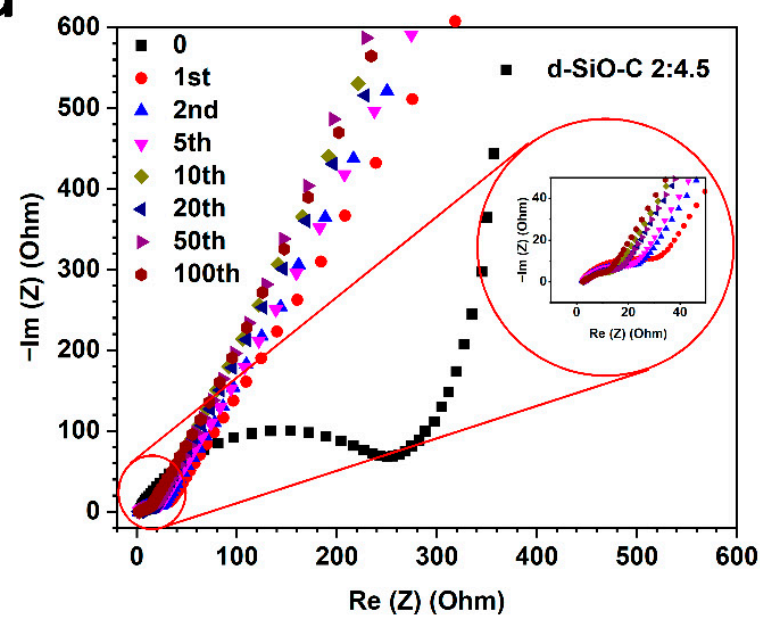

f

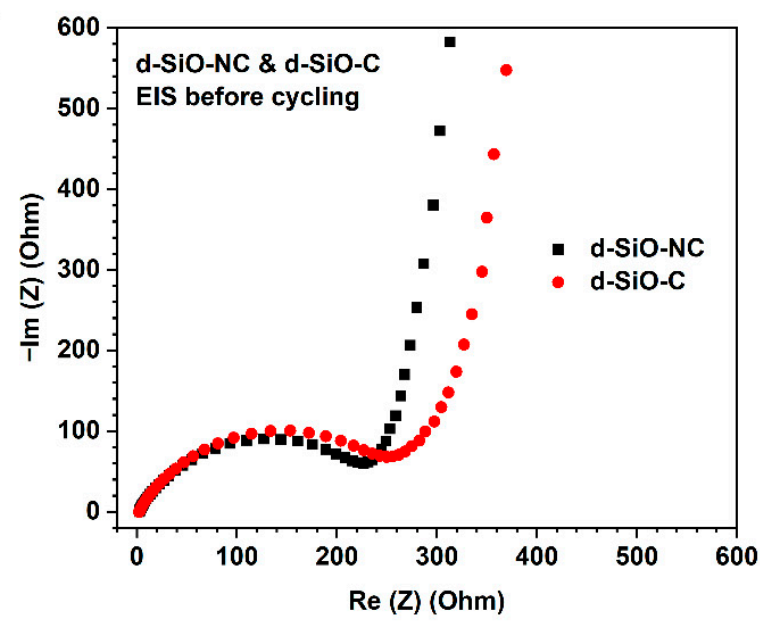

Figure 7. Cyclic voltammetry curve of first 5 cycles of d-SiO-NC (2:1.5:3) (a) and d-SiO-C (2:4.5) (b). Electrochemical impedance spectroscopy after different cycles of d-SiO-NC (2:1.5:3) (c) and d-SiO-C (2:4.5) (d). Comparison of first-cycle CV curve (e) and EIS spectroscopy (f) between d-SiO-NC (2:1.5:3) and d-SiO-C (2:4.5). (g) The equivalent circuits of EIS analysis. 
In Figure 7c,d, the EIS spectra after different cycles of both d-SiO-NC (2:1.5:3) and d-SiO-C (2:4.5) based half cells are shown. "0" means the EIS was operated before starting cycling. The comparison of EIS spectra during the first cycle between two materials is shown in Figure 7f. These EIS spectra were fitted based on the equivalent circuit shown in Figure $7 \mathrm{~g}$ and the fitting results are shown in Table 2. $R_{s}$ represents the ohmic resistance (resistance between the electrode and electrolyte), $R_{f}$ means the resistance of solid electrolyte film and $R_{c t}$ represents the resistance of charge transfer. The inclined line is corresponded to the lithium ion diffusion process, representing the Warburg impedance $\left(Z_{w}\right)$. According to the fitting results in Table 2, it suggested that the $R_{s}$ is similar in two kinds of cells, while the $R_{f}$ and $R_{c t}$ of d-SiO-NC based cells are lower than d-SiO-C based cells. Before cycling, the $R_{f}$ reduced from $285.3 \Omega$ to $243.2 \Omega$ after $\mathrm{N}$-doping. the results after cycling also shows an obvious decrease. In conclusion, these EIS spectra and fitting results suggests that d-SiO-NC (2:1.5:3) could provide better lithium ion transfer conductivity. These results are in accordance with the results of the long cycling performance at a high current density.

Table 2. The values of ohmic, solid electrolyte film and charge transfer of d-SiO-C (2:4.5) and d-SiO-NC (2:1.5:3).

\begin{tabular}{ccccc}
\hline Sample & Conditions & $\boldsymbol{R}_{\boldsymbol{s}}(\boldsymbol{\Omega})$ & $\boldsymbol{R}_{\boldsymbol{f}}(\boldsymbol{\Omega})$ & $\boldsymbol{R}_{\boldsymbol{c t}}(\boldsymbol{\Omega})$ \\
\hline \multirow{2}{*}{ d-SiO-C (2:4.5) } & Before cycle & 2.269 & 285.3 & $\sim 0$ \\
& After 5th cycles & 2.097 & 20.03 & 49.39 \\
& After 50th cycles & 3.549 & 17.12 & 45.50 \\
\hline \multirow{2}{*}{ d-SiO-NC } & Before cycle & 2.181 & 243.2 & $\sim 0$ \\
(2:1.5:3) & After 5th cycles & 2.18 & 12.62 & 21.15 \\
& After 50th cycles & 2.40 & 12.81 & 13.12 \\
\hline
\end{tabular}

To investigate the transport of lithium ions further, the lithium ion chemical diffusion coefficient $\left(D_{\mathrm{Li}^{+}}\right)$could be calculated by EIS and CV method according to the literature [38]. Using EIS method, $D_{L i^{+}}$can be calculated by the following equation:

$$
D_{L i^{+}}=\frac{R^{2} T^{2}}{2 n_{L i^{+}}^{4} A^{2} F^{4} C_{L i^{+}}^{2} \sigma_{W}^{2}}
$$

In this equation, $R$ represents the gas constant $\left(8.314 \mathrm{~J} \mathrm{~mol}^{-1} \mathrm{~K}^{-1}\right), T$ represents temperature in Kelvin $(298.15 \mathrm{~K}), n_{\mathrm{Li}^{+}}$represents the number of electrons per species reaction (for lithium ions, $\left.n_{\mathrm{Li}^{+}}=1\right)$, A represents the surface area of electrode $\left(1.131 \mathrm{~cm}^{2}\right), F$ means Faraday constant $\left(96485 \mathrm{C} \mathrm{mol}^{-1}\right), C_{\mathrm{Li}^{+}}$represents the concentration of lithium ions in $\mathrm{mol} \mathrm{cm}^{-3}\left(0.06323 \mathrm{~mol} \mathrm{~cm}^{-3}\right.$ and $0.05822 \mathrm{~mol} \mathrm{~cm}^{-3}$ for d-SiO-C (2:4.5) and d-SiO-NC (2:1.5:3) respectively calculated by molar mass and density of two kinds of active materials) and $\sigma_{W}$ means the Warburg coefficient, which can be obtained in the real part of impedance $(\operatorname{Re}(Z))$ vs. $\omega^{-1 / 2}$ graphs (Figure 8$)$. The relationship between $\operatorname{Re}(Z)$ and square root of inverse angular frequency $\left(\omega^{-1 / 2}\right)$ can be described as equations in Equation (2) and the slope represents the $\sigma_{W}$.

$$
\operatorname{Re}(Z)=R_{\text {ohmic }}+R_{c t}+\sigma_{W} \omega^{-1 / 2}
$$

In this equation, $\omega$ represents the angular frequency, which is the same as $2 \pi f$ in which $f$ means the frequency in Hertz. After linear fitting of $\operatorname{Re}(\mathrm{Z})$ and $\omega^{-1 / 2}, \sigma_{W}$ can be calculated in after different cycles of cells, which is shown in Table 3. Based on equal (1), $D_{\mathrm{Li}^{+}}$can be calculated and shown in Table 3. Compared the value in table, it could be indicated that the $D_{\mathrm{Li}^{+}}$is higher in d-SiO-NC than d-SiO-C, demonstrating that the doping of $\mathrm{N}$ could contribute the transport of lithium ions. 
a

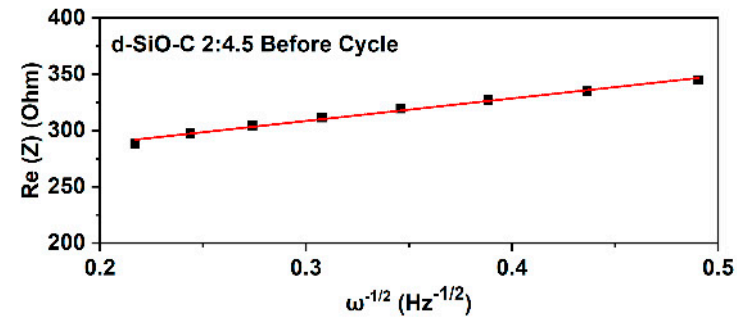

b

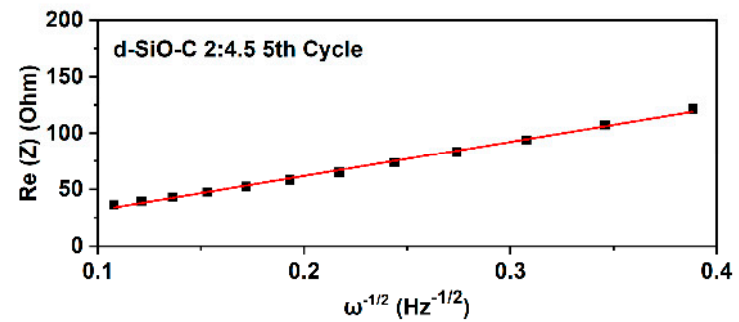

C

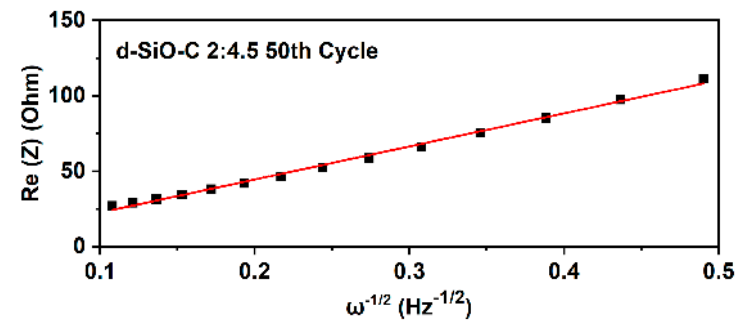


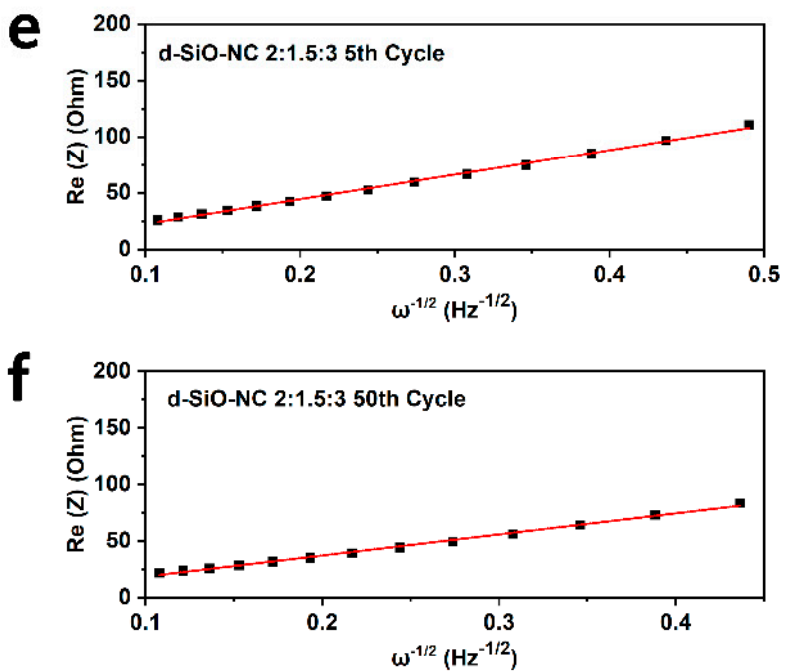

Figure 8. The relationship between $\operatorname{Re}(\mathrm{Z})$ and square root of inverse angular frequency, $\omega^{-1 / 2}$ in low frequency region for d-SiO-C/ / Li cell (a) before cycle, (b) after 5th cycle and (c) after 50th cycle, and d-SiO-NC// Li cell (d) before cycle, (e) after 5th cycle and (f) after 50th cycle.

Table 3. Warburg coefficient and lithium ion chemical diffusion coefficient calculated by EIS methods.

\begin{tabular}{cccc}
\hline Cells & Conditions & $\sigma_{W}\left(\boldsymbol{\Omega} \mathbf{~ c m}^{\mathbf{2}} \mathbf{s}^{-\mathbf{0 . 5}}\right)$ & $\boldsymbol{D}_{\mathbf{L i}^{+}}\left(\mathbf{c m}^{\mathbf{2}} \mathbf{s}^{-\mathbf{1}}\right)$ \\
\hline \multirow{3}{*}{$\mathrm{d}-\mathrm{SiO}-\mathrm{C} / / \mathrm{Li}$} & Before cycling & 200.8 & $1.72 \times 10^{-16}$ \\
& After the 5th cycle & 304.42 & $7.48 \times 10^{-17}$ \\
& After the 50th cycle & 219.3 & $1.44 \times 10^{-16}$ \\
\hline \multirow{3}{*}{$\mathrm{d}-\mathrm{SiO}-\mathrm{NC} / / \mathrm{Li}$} & Before cycling & 153.31 & $3.47 \times 10^{-16}$ \\
& After the 5th cycle & 218.77 & $1.70 \times 10^{-16}$ \\
& After the 50th cycle & 186.46 & $2.35 \times 10^{-16}$ \\
\hline
\end{tabular}

Figure 9a,b shows the CV characteristics of d-SiO-C (2:4.5) and d-SiO-NC (2:1.5:3) under different scan rates. It can be found that with the increase of scan rate, the peak current $\left(I_{p}\right)$ increases gradually and the peak potential in cathode scan shifts to higher on in both two kinds of cells. In CV curve under a scan rate of $0.1 \mathrm{mV} \mathrm{s}^{-1}$ (Figure 7a,b), two oxidation peaks and two reduction peaks could be found clearly, while if scan rate rises to more than $1 \mathrm{mV} \mathrm{s}^{-1}$, only one pair of redox peaks could be found, which is in accordance with Teo's work [36]. Based on the $I_{p}$ in Figure 9a,b, in which displays the relationship between $I_{p}$ and $v^{1 / 2}$, it could be recognized that the lithiation/de-lithiation processes are diffusion-controlled, and $D_{\mathrm{Li}^{+}}$based on $\mathrm{CV}$ data could be calculated using the following Randles-Sevcik equation [38]:

$$
I_{p}=\left(2.69 \times 10^{5}\right) n_{\mathrm{Li}^{+}}^{3 / 2} A D_{\mathrm{Li}^{+}}^{1 / 2} \mathrm{C}_{\mathrm{Li}^{+}} v^{1 / 2}
$$


a
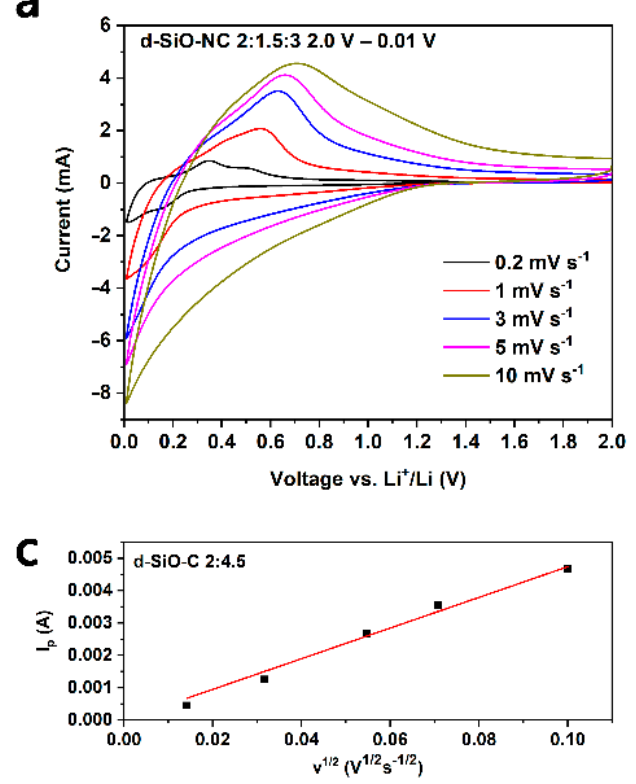

b
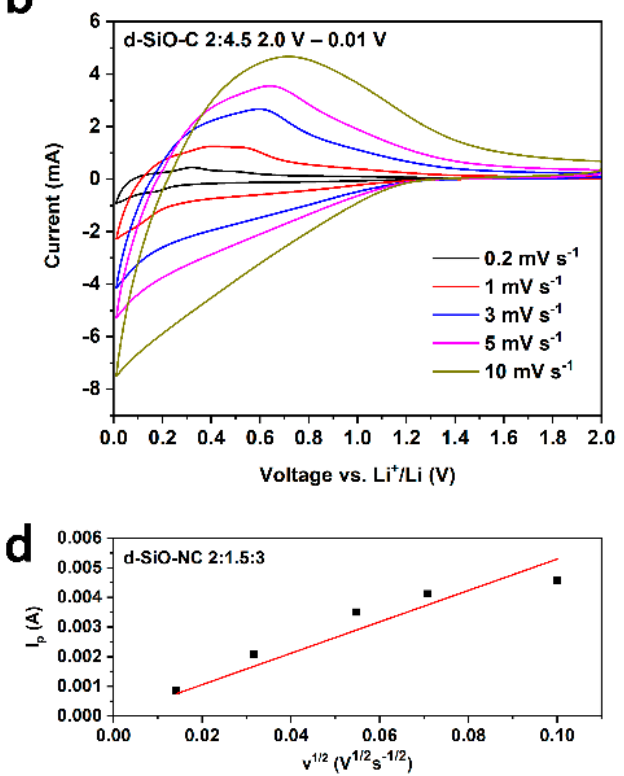

Figure 9. Cyclic voltammetry curves of d-SiO-C (2:4.5) (a) and d-SiO-NC (2:1.5:3) (b) in different scan rate. Peak current, $I_{p}$ as a function of square root of scan rate, $v^{1 / 2}$ of d-SiO-C (2:4.5) (c) and d-SiO-NC (2:1.5:3) (d).

In this equation, $I_{p}$ represents the peak current of $C V$ curves in ampere, and $v^{1 / 2}$ represents the scan rate in $\mathrm{mV} \mathrm{s}^{-1}$. The meanings of $n_{\mathrm{Li}^{+}}, A, D_{\mathrm{Li}^{+}}$, and $C_{\mathrm{Li}^{+}}$have been mentioned previously. The slope of fitted line in Figure $9 \mathrm{c}, \mathrm{d}$ could be used to calculate the $D_{\mathrm{Li}^{+}}$. The results are $6.07 \times 10^{-12} \mathrm{~cm}^{2} \mathrm{~s}^{-1}$ and $8.94 \times 10^{-12} \mathrm{~cm}^{2} \mathrm{~s}^{-1}$ for d-SiO-C (2:4.5) and d-SiO-NC (2:1.5:3) respectively. The $D_{\mathrm{Li}^{+}}$calculated by CV curves could also suggest that the doping of $\mathrm{N}$ could improve the transport of lithium ions. The results of $D_{\mathrm{Li}^{+}}$ calculated by $\mathrm{CV}$ analysis is about several orders of magnitude higher than that calculated by EIS analysis, which may because of the system and internal error. This phenomenon is accordance with results reported in other literatures [36].

\subsection{Pre-Lithiate d-SiO-NC Anode and Full Cell Test}

Though d-SiO-NC-based half cells deliver a stable cycling performance even at a high current, they perform a low ICE during the cycling process (approximately $56 \%$ ), which is a fatal disadvantage in practical application. To enhance ICE, SLMP-SBR-Toluene (SST) suspension was used to pre-lithiate d-SiO-NC (2:1.5:3) anode. $16 \mu \mathrm{L}$ SST suspension, with $1 \mathrm{wt} \%$ of SLMP, was added to the surface of the electrode. Then electrode with SST was treated in the same way as we reported before [19]. The initial Coulombic efficiency was improved to around $101 \%$ in half cells (Figure 10a). The Coulombic efficiency of the first several cycles is also higher than d-SiO-NC (2:1.5:3) without pre-lithiation. The pre-lithiated d-SiO-NC (2:1.5:3) electrodes were used to assemble full cells. The decrease of Coulombic efficiency at the 6th cycle is because the specific current was enhanced to $1000 \mathrm{~mA} \mathrm{~g}^{-1}$ (at the end of activation).

To verify its promise in practical application, $\mathrm{LiNi}_{0.6} \mathrm{Mn}_{0.2} \mathrm{Co}_{0.2} \mathrm{O}_{2}$ (NMC 622) was used as cathode material to assemble full cells. The electrolyte, separator in full cells and the process of assembling are the same as that of half cells. The assembled full cells were charged and discharged at a specific current of $0.1 \mathrm{C}$ based on the mass of cathode materials. As shown in Figure 10b, after 40 cycles, the specific capacity of full cells could keep around $80 \mathrm{~mA} \mathrm{~h} \mathrm{~g}^{-1}$ (based on the mass of NMC 622). Meanwhile, there is also a stable Coulombic efficiency after around 10 cycles. This kind of material has a potential value to be used in lithium ion full cells. 
a

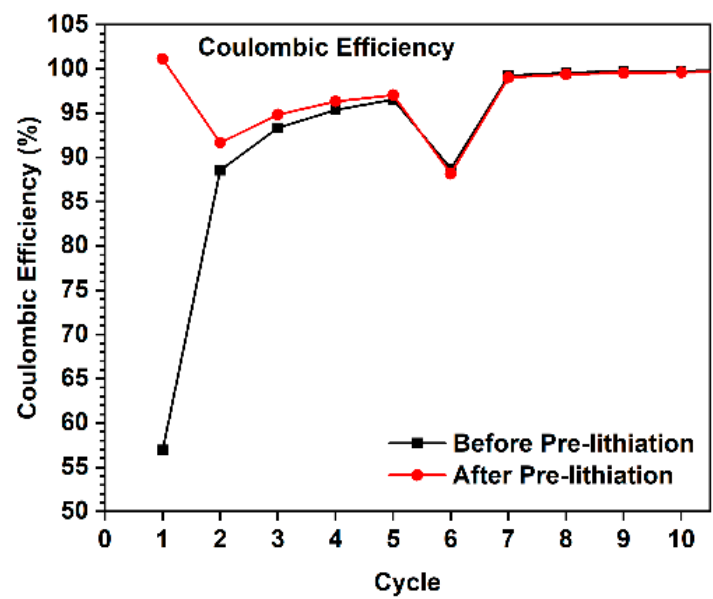

b

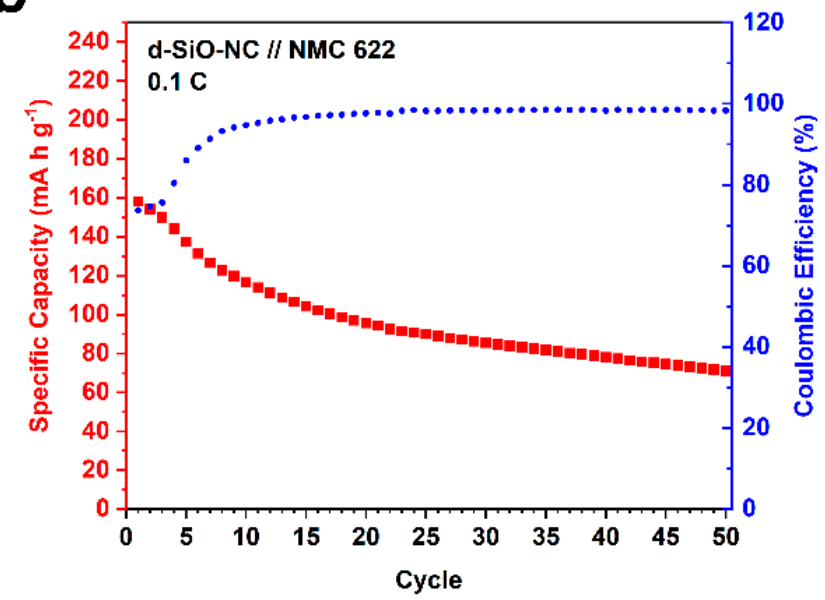

Figure 10. (a) Coulombic efficiency of first several cycles in cycling test of d-SiO-NC (2:1.5:3) before and after pre-lithiation. (b) Cycling performance of full cell fabricated by pre-lithiated d-SiO-NC (2:1.5:3) and $\mathrm{LiNi}_{0.6} \mathrm{Mn}_{0.2} \mathrm{Co}_{0.2} \mathrm{O}_{2}(\mathrm{NMC} 622)$.

\section{Materials and Methods}

\subsection{Material Synthesis}

All materials were obtained by producers and used in experiment without further treatment. In particularly, pitch, extracted from crude oil and mostly made up of $C$, is a kind of complex mixture composed with hydrocarbon in different molecular weight and other non-metal composites. The schematic illustration of the preparation of d-SiO-NC is shown in Figure 1. d-SiO was produced by the disproportion of $\mathrm{SiO}$ powder (Rijinwen Silicon Co., Peixian, China, 99.95\%, D(50): $3 \mu \mathrm{m}$, specific area: $2.11 \mathrm{~m}^{2} \mathrm{~g}^{-1}$ ) at $900{ }^{\circ} \mathrm{C}$ under an argon atmosphere. d-SiO, pitch (Tianjin HX Chemicals Co., Ltd., Tianjin, China; softening point: $300^{\circ} \mathrm{C}$.) and melamine (AR grade, Sinopharm Chemical Reagent Co., Ltd., Shanghai, China) were mixed with a certain mass ratio in a beaker. $30-40 \mathrm{~mL}$ of $\mathrm{DI} \mathrm{H}_{2} \mathrm{O}$ (deionized water) was added and the obtained suspension was dispersed under ultrasound for 20-30 min to make d-SiO, pitch and melamine dispersed evenly in $\mathrm{H}_{2} \mathrm{O}$. Then the suspension was heated to $55-60{ }^{\circ} \mathrm{C}$ with mechanical stirring to solvent was evaporated completely. The residue was transferred to tube furnace and heated to $300^{\circ} \mathrm{C}$ for $7 \mathrm{~h}$ in an argon atmosphere, then the temperature was increased to $700^{\circ} \mathrm{C}$ for $3 \mathrm{~h}$ to make pitch and melamine carbonize. The $\mathrm{d}-\mathrm{SiO}-\mathrm{NC}$ was produced after cooling and used to prepare anode for lithium ion batteries directly. Three different ratios of d-SiO, melamine and pitch $(2: 2: 4,2: 1.5: 3$ and 2:1:2) were prepared. For d-SiO-C and $\mathrm{SiO}-\mathrm{NC}$, the preparation methods are the same as mentioned above except that melamine was replaced by pitch or $\mathrm{d}-\mathrm{SiO}$ was replaced by $\mathrm{SiO}$.

\subsection{Material Characterization}

To analyze the morphology of active materials, XRD (D8 Discover, Bruker, karlsruhe, Germany) with $\mathrm{Cu}-\mathrm{K} \alpha$ radiation was utilized. Field-emission scanning electron microscopy (FESEM, S-4800, Hitachi Co., Tokyo, Japan) was used. X-ray photoelectron spectroscopy (XPS, Perkin Elmer Co., Waltham, MA, USA) was adopted to analyze the N and C on active materials particles using $\mathrm{Al} \mathrm{K} \alpha$ radiation $(\mathrm{h} v=1486.6 \mathrm{eV})$. The microstructure of the coating layer and the distribution of elements were observed by transmission electron microscopy (TEM, JEOL 2010F, JEOL, Tokyo, Japan).

\subsection{Preparation of Electrode}

For working electrode, active materials, conductive reagent (Super P, MTI Co., Shenzhen, China), and binder (sodium alginate, CP grade, Sinopharm Chemical Reagent Co., Ltd.) were mixed and grounded with a mass ratio of 6:2:2. Then a certain amount of DI $\mathrm{H}_{2} \mathrm{O}$ was added in the mixture to produce slurry, which was cast on the $\mathrm{Cu}$ foil (MTI Co., 
thickness: approximately $10.5 \mu \mathrm{m})$. Then the electrode was dried in oven at $100{ }^{\circ} \mathrm{C}$ for $4 \mathrm{~h}$ and cut into discs with the diameter of $12 \mathrm{~mm}$. The discs were then dried in a vacuum condition at $80^{\circ} \mathrm{C}$ for $12 \mathrm{~h}$ and transferred into a glovebox (Superstar 1220, moisture and oxygen below 0.5 ppm, Mikrouna, Shanghai, China) filled with argon atmosphere for the fabrication of cells or pre-lithiated. The average mass loading of active material in each anode was around $0.86 \mathrm{mg} \mathrm{cm}^{-2}$.

For cathode, $\mathrm{LiNi}_{0.6} \mathrm{Mn}_{0.2} \mathrm{Co}_{0.2} \mathrm{O}_{2}$ (NMC622, Umicore Finland Oy, Kokkola, Finland) cathode was prepared as the following instruction: $80 \mathrm{wt} \%$ of NMC622, $10 \mathrm{wt} \%$ of Super $\mathrm{P}$ (conductive reagent) and $10 \mathrm{wt} \%$ of poly(1,1-difluoroethylene) (PVDF, binder, MTI Co.) were mixed in moderate N-Methyl pyrrolidone (NMP, 99\%, J\&K Scientific, Beijing, China,), then the obtained slurry was cast on the Al foil (GRINM Group, Beijing, China, thickness: $20 \mu \mathrm{m})$. After drying and cutting to the discs with a diameter of $12 \mathrm{~mm}$, cathode electrodes were pressed at about $10 \mathrm{MPa}$ for approximately $60 \mathrm{~s}$. The average mass loading of NMC622 was $7.09 \mathrm{mg} \mathrm{cm}^{-2}$.

\subsection{The Fabrication of Cells}

CR2016 coin half cells were fabricated with working electrode, separator (made up of cellulose, NKK, city, Japan) and the reference electrode (lithium foil, Zhong Neng Co., Tianjin, China. $\Phi 16 \mathrm{~mm} \times 1.0)$. About $0.1 \mathrm{~mL}$ electrolyte containing $1 \mathrm{M} \mathrm{LiPF}_{6}$ in ethylene carbonate (EC)—diethyl carbonate (DEC) (1:1 vol\%) containing 10\% fluoroethylene carbonate (FEC) was added in coin cells. The electrolyte was produced by Nanjing Modges Energy Tech (Nanjing, China), and the water content is less than 10 ppm. Pre-lithiation process proposed by our reported work [19] was operated before full cells were fabricated. Full cells were fabricated by working electrode, separator and cathode. The N/P capacity ratio of full cells were 1.2 approximately. The same kind of separator and electrolyte were used in both full cells and half cells.

\subsection{Electrochemical Test of Cells}

Charging and discharging cycle was measured by CT2001A Land Batteries Testing System (Wuhan Land Electronic Co. Ltd., Wuhan, China). For cycling performance, half cells were discharged and charged at a small specific current of $100 \mathrm{~mA} \mathrm{~g}^{-1}$ for 5 cycles before a large specific current of 1000 or $2000 \mathrm{~mA} \mathrm{~g}^{-1}$. Full cells were charged and discharged at $0.1 \mathrm{C}\left(18 \mathrm{~mA} \mathrm{~g}^{-1}\right)$ based on the mass of cathode materials for several cycles.

Cyclic voltammetry (CV) and electrochemical impedance spectroscopy (EIS) test were operated on VSP-300 electrochemical workstation (Bio-Logic China Company, Shanghai, China). CR2016 coin half cells fabricated by the method mentioned in Section 3.4 were used to operate CV and EIS test. For the CV test, the voltage started at open circuit voltage $(\mathrm{OCV})$ and reversed scan to $0.01 \mathrm{~V}$ and then scan to $2.0 \mathrm{~V}$ with a scan rate of $0.1 \mathrm{mV} \mathrm{s}^{-1}$. During the calculation of $D_{\mathrm{Li}^{+}}$, the CV curves were obtained in different scan rate of $0.2,1$, 3,5 and $10 \mathrm{mV} \mathrm{s}^{-1}$. For the EIS test, the frequency ranges from $1 \mathrm{MHz}-1 \mathrm{mHz}$.

\section{Conclusions}

In conclusion, a cheap and convenient strategy to produce N-doped C-coating disproportionated $\mathrm{SiO}$ (d-SiO-NC) to be used as anode material for high-energy lithium ion batteries was reported. A relatively high reversible specific capacity $\left(400 \mathrm{~mA} \mathrm{~h} \mathrm{~g}{ }^{-1}\right)$ and stable cycling performance could be delivered even at a high specific current of $2000 \mathrm{~mA}$ $\mathrm{g}^{-1}$. Based on the conclusion reported in literature [29], the addition of $\mathrm{N}$ could improve capacity and cycling retention further because some kinds of $\mathrm{N}$, which were analyzed by XPS, could produce active sites in the carbon layer, contributing to the transport of lithium ions. Several ratios of $\mathrm{d}-\mathrm{SiO}$, pitch and melamine were investigated to get an overall good capability. CV and EIS tests were operated to investigate the mechanism of intercalation and extraction of active materials. Then, the pre-lithiation strategy was operated on $\mathrm{d}$ $\mathrm{SiO}-\mathrm{NC}$ anode electrode to improve the initial Coulombic efficiency. $\mathrm{LiNi}_{0.6} \mathrm{Mn}_{0.2} \mathrm{Co}_{0.2} \mathrm{O}_{2}$ (NMC 622) was used to assemble full cells to verify its practical application. What's more, 
the low cost of pitch and melamine and the convenient producing process of this material contribute to its practical application in industry. The stability of cycling at a high current also makes it available on many kinds of instruments and situations.

Author Contributions: Conceptualization, B.H. and A.Y.; methodology, B.H.; validation, T.H. and A.Y.; formal analysis, B.H.; investigation, B.H. and B.C.; resources, B.H. and B.C.; data curation, B.H.; writing—original draft preparation, B.H.; writing-review and editing, B.H., T.H. and A.Y.; supervision, T.H. and A.Y.; project administration, A.Y.; funding acquisition, A.Y. All authors have read and agreed to the published version of the manuscript.

Funding: This research was funded by Science \& Technology Commission of Shanghai Municipality, China, grant number 19DZ2270100.

Institutional Review Board Statement: “Not applicable” for studies not involving humans or animals. Informed Consent Statement: “Not applicable” for studies not involving humans.

Data Availability Statement: Data is contained within the article.

Acknowledgments: All authors are grateful for the support by Science \& Technology Commission of Shanghai Municipality, China. (No. 19DZ2270100).

Conflicts of Interest: The authors declare no conflict of interest.

Sample Availability: Samples of the compounds d-SiO-C, d-SiO-NC and SiO-NC are available from the authors.

\section{References}

1. Armstrong, G. The Li-ions share. Nat. Chem. 2019, 11, 1076. [CrossRef] [PubMed]

2. Zeng, X.; Li, M.; Abd El-Hady, D.; Alshitari, W.; Al-Bogami, A.S.; Lu, J.; Amine, K. Commercialization of Lithium Battery Technologies for Electric Vehicles. Adv. Energy Mater. 2019, 9, 1900161. [CrossRef]

3. Schmuch, R.; Wagner, R.; Hörpel, G.; Placke, T.; Winter, M. Performance and cost of materials for lithium-based rechargeable automotive batteries. Nat. Energy 2018, 3, 267-278. [CrossRef]

4. Chu, B.; Liu, S.; You, L.; Liu, D.; Huang, T.; Li, Y.; Yu, A. Enhancing the Cycling Stability of Ni-Rich $\mathrm{LiNi}_{0.6} \mathrm{Co}_{0.2} \mathrm{MO}_{2} \mathrm{Cathode} \mathrm{at} \mathrm{a}$ High Cutoff Voltage with Ta Doping. ACS Sustain. Chem. Eng. 2020, 8, 3082-3090. [CrossRef]

5. Liu, D.; Liu, S.; Zhang, C.; You, L.; Huang, T.; Yu, A. Revealing the Effect of Ti Doping on Significantly Enhancing Cyclic Performance at a High Cutoff Voltage for Ni-Rich $\mathrm{LiNi}_{0.8} \mathrm{Co}_{0.15} \mathrm{Al}_{0.05} \mathrm{O}_{2}$ Cathode. ACS Sustain. Chem. Eng. 2019, 7, 10661-10669. [CrossRef]

6. Liu, S.; Wang, L.; Zhang, C.; Chu, B.; Wang, C.; Huang, T.; Yu, A. Dynamic evolution of Cathode-Electrolyte interface of $\mathrm{LiNi}_{0.6} \mathrm{Co}_{0.2} \mathrm{Mn}_{0.2} \mathrm{O}_{2}$ during the initial Charge-Discharge process. J. Power Sources 2019, 438, 226979. [CrossRef]

7. Chen, H.; Xiao, Y.; Wang, L.; Yang, Y. Silicon nanowires coated with copper layer as anode materials for lithium-ion batteries. J. Power Sources 2011, 196, 6657-6662. [CrossRef]

8. Ruttert, M.; Siozios, V.; Winter, M.; Placke, T. Mechanochemical Synthesis of Fe-Si-Based Anode Materials for High-Energy Lithium Ion Full-Cells. ACS Appl. Energy Mater. 2020, 3, 743-758. [CrossRef]

9. Müller, J.; Abdollahifar, M.; Vinograd, A.; Nöske, M.; Nowak, C.; Chang, S.-J.; Placke, T.; Haselrieder, W.; Winter, M.; Kwade, A.; et al. Engineering Si-on-Graphite High-Capacity Anodes for Li-ion Battery Applications Fabricated by Fluidized Bed Process. Chem. Eng. J. 2020, 407, 126603. [CrossRef]

10. Boukamp, B.A.; Lesh, G.C.; Huggins, R.A. All-Solid Lithium Electrodes with Mixed-Conductor Matrix. J. Electrochem. Soc. 1981, 128, 725-729. [CrossRef]

11. Liang, B.; Liu, Y.; Xu, Y. Silicon-based materials as high capacity anodes for next generation lithium ion batteries. J. Power Sources 2014, 267, 469-490. [CrossRef]

12. Li, J.-Y.; Xu, Q.; Li, G.; Yin, Y.-X.; Wan, L.-J.; Guo, Y.-G. Research progress regarding Si-based anode materials towards practical application in high energy density Li-ion batteries. Mater. Chem. Front. 2017, 1, 1691-1708. [CrossRef]

13. Zuo, X.; Zhu, J.; Müller-Buschbaum, P.; Cheng, Y.-J. Silicon based lithium-ion battery anodes: A chronicle perspective review. Nano Energy 2017, 31, 113-143. [CrossRef]

14. Wu, H.; Cui, Y. Designing nanostructured Si anodes for high energy lithium ion batteries. Nano Today 2012, 7, 414-429. [CrossRef]

15. Ashuri, M.; He, Q.; Shaw, L.L. Silicon as a potential anode material for Li-ion batteries: Where size, geometry and structure matter. Nanoscale 2016, 8, 74-103. [CrossRef] [PubMed]

16. Holzapfel, M.; Buqa, H.; Hardwick, L.J.; Hahn, M.; Würsig, A.; Scheifele, W.; Novák, P.; Kötz, R.; Veit, C.; Petrat, F.-M. Nano silicon for lithium-ion batteries. Electrochim. Acta 2006, 52, 973-978. [CrossRef]

17. Beaulieu, L.Y.; Eberman, K.W.; Turner, R.L.; Krause, L.J.; Dahn, J.R. Colossal Reversible Volume Changes in Lithium Alloys. Electrochem. Solid State Lett. 2001, 4, A137-A140. [CrossRef] 
18. Liu, Z.; Yu, Q.; Zhao, Y.; He, R.; Xu, M.; Feng, S.; Li, S.; Zhou, L.; Mai, L. Silicon oxides: A promising family of anode materials for lithium-ion batteries. Chem. Soc. Rev. 2019, 48, 285-309. [CrossRef] [PubMed]

19. Huang, B.; Huang, T.; Wan, L.; Yu, A. Pre-Lithiating SiO Anodes for Lithium-Ion Batteries by a Simple, Effective, and Controllable Strategy Using Stabilized Lithium Metal Powder. ACS Sustain. Chem. Eng. 2021, 9, 648-657. [CrossRef]

20. Yu, B.-C.; Hwa, Y.; Kim, J.-H.; Sohn, H.-J. A New Approach to Synthesis of Porous SiOx Anode for Li-ion Batteries via Chemical Etching of Si Crystallites. Electrochim. Acta 2014, 117, 426-430. [CrossRef]

21. Yu, B.-C.; Hwa, Y.; Park, C.-M.; Sohn, H.-J. Reaction mechanism and enhancement of cyclability of SiO anodes by surface etching with $\mathrm{NaOH}$ for Li-ion batteries. J. Mater. Chem. A 2013, 1, 4820-4825. [CrossRef]

22. Hwa, Y.; Park, C.M.; Sohn, H.J. Modified SiO as a high performance anode for Li-ion batteries. J. Power Sources 2013, 222, 129-134. [CrossRef]

23. Doh, C.-H.; Park, C.-W.; Shin, H.-M.; Kim, D.-H.; Chung, Y.-D.; Moon, S.-I.; Jin, B.-S.; Kim, H.-S.; Veluchamy, A. A new SiO/C anode composition for lithium-ion battery. J. Power Sources 2008, 179, 367-370. [CrossRef]

24. Kim, J.-H.; Sohn, H.-J.; Kim, H.; Jeong, G.; Choi, W. Enhanced cycle performance of SiO-C composite anode for lithium-ion batteries. J. Power Sources 2007, 170, 456-459. [CrossRef]

25. Morita, T.; Takami, N. Nano Si Cluster-SiO - -C Composite Material as High-Capacity Anode Material for Rechargeable Lithium Batteries. J. Electrochem. Soc. 2006, 153, A425-A430. [CrossRef]

26. Yamada, M.; Ueda, A.; Matsumoto, K.; Ohzuku, T. Silicon-Based Negative Electrode for High-Capacity Lithium-Ion Batteries: "SiO"-Carbon Composite. J. Electrochem. Soc. 2011, 158, A417-A421. [CrossRef]

27. Choi, I.; Lee, M.J.; Oh, S.M.; Kim, J.J. Fading mechanisms of carbon-coated and disproportionated Si/SiOx negative electrode $\left(\mathrm{Si} / \mathrm{SiO}_{\mathrm{x}} / \mathrm{C}\right)$ in Li-ion secondary batteries: Dynamics and component analysis by TEM. Electrochim. Acta 2012, 85, 369-376. [CrossRef]

28. Kim, K.W.; Park, H.; Lee, J.G.; Kim, J.; Kim, Y.-U.; Ryu, J.H.; Kim, J.J.; Oh, S.M. Capacity variation of carbon-coated silicon monoxide negative electrode for lithium-ion batteries. Electrochim. Acta 2013, 103, 226-230. [CrossRef]

29. Xing, Y.; Zhang, L.; Mao, S.; Wang, X.; Wenren, H.; Xia, X.; Gu, C.; Tu, J. Core-shell structure of porous silicon with nitrogen-doped carbon layer for lithium-ion batteries. Mater. Res. Bull. 2018, 108, 170-175. [CrossRef]

30. Lee, D.J.; Ryou, M.-H.; Lee, J.-N.; Kim, B.G.; Lee, Y.M.; Kim, H.-W.; Kong, B.-S.; Park, J.-K.; Choi, J.W. Nitrogen-doped carbon coating for a high-performance $\mathrm{SiO}$ anode in lithium-ion batteries. Electrochem. Commun. 2013, 34, 98-101. [CrossRef]

31. Park, C.-M.; Choi, W.; Hwa, Y.; Kim, J.-H.; Jeong, G.; Sohn, H.-J. Characterizations and electrochemical behaviors of disproportionated $\mathrm{SiO}$ and its composite for rechargeable Li-ion batteries. J. Mater. Chem. 2010, 20, 4854-4860. [CrossRef]

32. Shen, T.; Xie, D.; Tang, W.; Wang, D.; Zhang, X.; Xia, X.; Wang, X.; Tu, J. Biomass-derived carbon/silicon three-dimensional hierarchical nanostructure as anode material for lithium ion batteries. Mater. Res. Bull. 2017, 96, 340-346. [CrossRef]

33. Philippe, B.; Dedryvère, R.; Allouche, J.; Lindgren, F.; Gorgoi, M.; Rensmo, H.; Gonbeau, D.; Edström, K. Nanosilicon Electrodes for Lithium-Ion Batteries: Interfacial Mechanisms Studied by Hard and Soft X-ray Photoelectron Spectroscopy. Chem. Mater. 2012, 24, 1107-1115. [CrossRef]

34. Miyachi, M.; Yamamoto, H.; Kawai, H.; Ohta, T.; Shirakata, M. Analysis of SiO Anodes for Lithium-Ion Batteries. J. Electrochem. Soc. 2005, 152, A2089-A2091. [CrossRef]

35. Shen, T.; Xia, X.-H.; Xie, D.; Yao, Z.-J.; Zhong, Y.; Zhan, J.-Y.; Wang, D.-H.; Wu, J.-B.; Wang, X.-L.; Tu, J.-P. Encapsulating silicon nanoparticles into mesoporous carbon forming pomegranate-structured microspheres as a high-performance anode for lithium ion batteries. J. Mater. Chem. A 2017, 5, 11197-11203. [CrossRef]

36. Teo, L.P.; Buraidah, M.H.; Arof, A.K. Study on $\mathrm{Li}+$ ion diffusion in $\mathrm{Li}_{2} \mathrm{SnO}_{3}$ anode material by CV and EIS techniques. Mol. Cryst. Liq. Cryst. 2020, 694, 117-130. [CrossRef]

37. Wang, H.; Xie, J.; Zhang, S.; Cao, G.; Zhao, X. Scalable preparation of silicon@graphite/carbon microspheres as high-performance lithium-ion battery anode materials. RSC Adv. 2016, 6, 69882-69888. [CrossRef]

38. Bard, A.J.; Faijlkner, L.R. Electrochemical Methods Fundamentals and Applications, 2nd ed.; John Wiley \& Sons, Inc.: Hoboken, NJ, USA, 2001. 